\title{
Magnitude of Psychoactive Substance Abuse among University Students, Adigrat, North Ethiopia: Cross Sectional Study
}

\author{
Tilahun Belete Mossie*, Gebrewahd Bezabh GebreMichael and Ashenafi Damte Ayele
}

Mekelle University, College of Health Sciences, Nursing department, Psychiatry Unit, Mekelle, Ethiopia

\begin{abstract}
Background: Substance abuse is a serious problem that interferes with an individual's physical and mental health, on the individual social situation and responsibilities. Of the young segment of the Ethiopian population, college and university students are the most at risk of using psychoactive substances. Its use among adolescents can be harmful, leading to decreased academic performance, increased risk of contracting HIVIAIDS including sexually transmitted diseases, and psychiatric disorders. Hence a need to conduct studies in this issue is fundamental and with the aim of determining the magnitude of psychoactive substance use among University students at Adigrat, this investigation was conducted.
\end{abstract}

Methodology: An institution based cross sectional study design using quantitative method was employed on 161 students; and after stratifying for department and batch, systematic random sampling was used to select study subjects. The study period was from April 1 to June 20,2014. Data was gathered by anonymous self-administer questionnaire using ASSIST and CAGE tools; also abuse was determined at a score of $\geq 2$ on CAGE.

Result: The magnitude of substance abuse was $16.7 \%$. The commonly abused substances were alcohol (8.7\%) followed by Khat $(6.7 \%)$; and cigarettes were abused by $6 \%$ of the participants. Comparably $3.33 \%$ and $2 \%$ were cannabis and cocaine abusers respectively. Peer pressure $29(34.52 \%)$, family pressure $25(29.76 \%)$, availability of the substances $17(20.24 \%)$, including religious purpose $3(3.57 \%)$ were common reasons to initiate extracting substances. In addition nearly half of them started using substances at the primary school level.

Recommendation: It is important to design suitable policies, culturally and psychologically appropriate intervention packages so as to tackle multiple effects of psychoactive substance abuse among University students.

Keywords: Psycho active substance; Abuse, Khat; University students; Adigrat University

\section{Introduction}

Psychoactive substance is any chemical substance which, when taken into the body, alters its function physically and/or psychologically (DSM IV). Psychoactive substance abuse is a maladaptive pattern of substance use leading to significant impairment or distress, which can be recurrent substance use resulting in a failure to fulfill major role obligations at work, school, or home (e.g., repeated absences or poor work performance related to substance use; substance-related absences, suspensions, or expulsions from school; neglect of children or household); persistent substance use in situations in which it is physically hazardous (e.g., driving an automobile or operating a machine when impaired by substance use); frequent substance-related legal problems (e.g., arrests for substance-related disorderly conduct); or continued substance use despite having persistent or recurrent social or interpersonal problems caused or exacerbated by the effects of the substance (e.g., arguments with spouse about consequences of intoxication, physical fights) (DSM IV).

Many countries including Ethiopia recognize that substance abuse by young people is a serious health and social problem. Students are among the high-risk population of substance abusers [1]. In Ethiopia, besides alcohol, Khat is commonly used for stimulation and social recreation. Khat, also called Catha edulis, amphetamine like substance which is a bush native to East Africa and Arabian Peninsula for more than thousand years is widely used in Ethiopia, Yemen, Somalia and Kenya; it is consumed by chewing the leaves of the plant [2]. A significant number of students consume Khat to be alert and wakeful at night, especially during examination periods (EPHA). Availability of substances, age, gender, having friends and families who use substances were the commonly mentioned factors that influence substances use [3-5]. Of the young segment of the Ethiopian population, college and University students are the most at risk of using alcohol and other drugs such as Khat and tobacco. Most often stimulant medications are increasingly used by high school and college students as a means to improve academic performance. Entering the university, often leads to new opportunities, independence from family control, self-decision making, and peer-pressures to use or abuse alcohol or other drugs [6]. The use of alcohol, Khat and tobacco among adolescents can be harmful, leading to decreased academic performance, increased risk of contracting HIV/AIDS and other Sexually Transmitted Diseases (STD), and psychiatric disorders such as, hopelessness and insomnia [6]. Furthermore, it exposes students to legal repercussions, or jeopardizes their enrollment at the university. Substance use behaviors among health science students have important implications for the health of the general population since health professionals are important role models in terms of health related behaviors [7-9].

*Corresponding author: ilahun Belete Mossie, Mekelle University, College of Health Sciences, Nursing Department, Psychiatry Unit, Mekelle, Ethiopia, Tel: +251913478099; E-mail: tilahunbe100@gmail.com

Received March 04, 2015; Accepted April 21, 2015; Published April 28, 2015

Citation: Mossie TB, GebreMichael GB, Ayele AD (2015) Magnitude of Psychoactive Substance Abuse among University Students, Adigrat, North Ethiopia: Cross Sectional Study. J Psychiatry 18: 281 doi: 10.4172/2378-5756.1000281

Copyright: (c) 2015 Mossie TB, et al. This is an open-access article distributed under the terms of the Creative Commons Attribution License, which permits unrestricted use, distribution, and reproduction in any medium, provided the original author and source are credited 
Even though substance use has become a common problem among university students in Ethiopia, only scant information is available that reflect its magnitude. Therefore, this study was conducted to determine the magnitude of psychoactive substance use among University students.

\section{Methods}

Study design and period: An institutional based cross sectional study with descriptive components was employed at Adigrat University from April 1 to June 20, 2014.

\section{Study population}

Source population: all students attending their education at Adigrat University.

Study population: health science college students who were attending under graduate course at Adigrat University.

\section{Eligibility criteria}

Inclusion criteria: Health science college students of Adigrat University attending under graduate level course.

Exclusion criteria: Unable to respond because of serious illness.

Sample size: with $95 \%$ confidence interval, $5 \%$ margin of error, 82.7\% proportion of substance use (Previous study at Mekelle University, North Ethiopia (Abrha) and then through administering a single proportion formula, the sample size was 220. Later after proceeding adjusting formula (Since the total population is less than ten thousand), and adding $10 \%$ non-response rate, the final sample size was $161[10]$.

Sampling procedure: through proportional allocation to departments, study participants were finally selected by systematic random sampling.

Data collection: self-administered questionnaire was employed and the data was collected using ASSIST (alcohol, smoking and substance involvement screening test) which was developed by World Health Organization to be used by all nations. Four Nursing 4 th year students were recruited for data collection.

Data Quality Control: The questionnaire was pretested on 15 Mekelle university students of the same college after translating in to local language (Amharic). Data collectors were trained for a day deeply to have common understanding regarding the questionnaire before data collection. Also 2 health professionals were supervising the data collection and providing appropriate guidance. Data clean up and cross-checking was done for completeness before data entry and analysis [11-14].

Data processing and analysis: data was entered and analyzed using 20 th version of SPSS software. Descriptive analysis was used to present the findings.

\section{Study variables}

Dependent variable: Psychoactive substance abuse.

Independent variables: socio demographic and clinical factors.

\section{Operational definitions}

Psychoactive substance user: the use of any of the psychoactive substances for non-medical purpose.
Ever use: The use of any of the psychoactive substances in life time.

Current use: The use of any of the psychoactive substances in the last 3 months.

Psychoactive substance abuse: Scoring 2 or more out of 4 in CAGE questionnaire.

Ethical consideration: the study was conducted after obtaining ethical clearance from Mekelle University, College of Health Sciences. In addition it was under taken after gaining permission from Adigrat University. Confidentiality and privacy of participants were assured; and those abusers were referred to mental health clinics.

Participants: About 150 students participated in the study making the response rate $93 \%$ (those who refuse to participate and incomplete questionnaires account 7\%). From thus, 107 (71.3\%) of the samples were males, the rest $43(28.7 \%)$ were females. Concerning age group $62 \%$ and $37 \%$ were (20-24) and (15-19) years respectively. The mean age and standard deviation of the participants were $20+2.8$ with a range of 17 to 28 years (Figure 1).

\section{Result}

Socio demographic characteristics: Around 77 (51.3\%) of the respondents was Tigrian followed by Amhara 41 (27.3\%). Out of the total respondents, $121(80.7 \%)$ were Orthodox followers, 14 (9.3\%) were Muslim. The prominent family occupation was farming among $66(44 \%)$ followed by governmental employee 31 (20.7\%). On the other hand the proportion of students by department was $38 \%$ from medicine and $24 \%, 20 \%$ and $18 \%$ from public health, midwifery and nursing departments respectively.

\section{Magnitude of psychoactive substance use}

Ever use of any psychoactive substance was $54 \%$. And alcohol was the most famous substance among 82 (54.7\%) of the students. Life time use of Khat, cigarettes, cannabis, cocaine, and diazepam was $14 \%, 8 \%$, $2.7 \%$. From among ever users; current use was $67 \%, 64 \%$ and $57 \%$ for cannabis, Khat and alcohol respectively. Magnitude of psychoactive substance abuse: of the total students, 25 of them fulfilled the criteria for abuse making the magnitude $16.7 \%$. Alcohol was the famous substance abused by $13(8.7 \%)$ of the students; besides that Khat and cigarettes were abused by $10(6.7 \%)$ and $9(6 \%)$ of the participants. Cannabis and cocaine abuse were also reported by $5(3.3 \%)$ and 3 (2\%) of the students. The reported reasons to initiate and to continue using psychoactive substances were different. Among the participants; peer pressure $29(34.5 \%)$, family pressure $25(29.8 \%)$, availability of the substances 17 (20.2\%), including religious purpose $3(3.6 \%)$ were

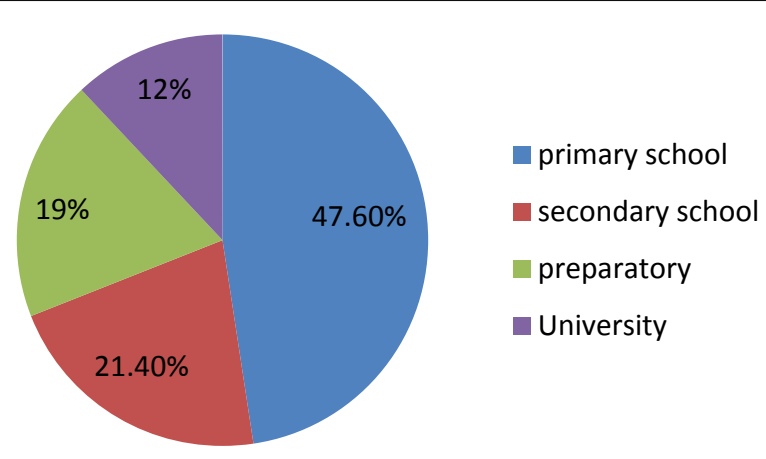

Figure 1: Distribution of University students by school level they started to extract substances, Adigrat University, Mar 2014. 
Citation: Mossie TB, GebreMichael GB, Ayele AD (2015) Magnitude of Psychoactive Substance Abuse among University Students, Adigrat, North Ethiopia: Cross Sectional Study. J Psychiatry 18: 281 doi: 10.4172/2378-5756.1000281

Page 3 of 4

common reasons to initiate extracting substances. On the other hand for relaxation 40 (47.6\%), to be alert $16(19 \%)$, to prevent stress 10 (11.9\%), for motivation $8(9.5 \%)$ and for other reasons 10 (11.9\%) were the reported rationale behind persistent use of substances.

\section{Discussion}

Prevalence of alcohol ever use was found to be $56 \%$. This prevalence rate was significantly higher than the findings obtained in Shiraz University students, Iran, 16\% (Sabhraian) [11]. In contrast this finding was relatively in agreement with result obtained in Haramaya University students, $53.8 \%$ (Derese) [12]. But it is remarkably lower than the report obtained from undergraduate students in Mekelle University, 82.7\% (Abrha) [10]. Our study shows that among psychoactive substance users, nearly half of them (47\%) started extracting substances at the age of primary school levels; which is relatively earlier when compared to similar study conducted at Ghana. In that study $56 \%$ of abusers started using substances in the age of 15-19 years [13]. The age an individual is not psychologically minded enough in coping to different stressors in the psycho social environment, which makes the use more persistent with potential of complicating future life [2]. This might be an indicator that awareness raising school based programs are poorly working or absent. This study revealed that $16.7 \%$ of the respondents fulfilled the criteria of substances abuse (CAGE $\geq 2$ ). This is relatively lower than the finding obtained among undergraduate Mekelle University students $20.1 \%$ (Abrha); the possible reason might be relatively poor control of illicit substances and wide cultivation as well as production of Khat and alcohol; which are not prohibited nationally.

The finding of this study on the proportional alcohol ever users (54.67\%)was relatively higher than reports from Ghana among in and out of school youth, 25\% (Kabiru), Haramaya university $41.7 \%$ (Derese) and Axum university 34.5\% (Gebreslassie) but extremely higher than the result obtained among Shiraz university students, Iran $1.1 \%$ (Sahraian). However it was relatively lower than the findings reported from undergraduate students of Mekelle University representing $69.7 \%$ (Abrha) $[14,15]$. In addition, based on this study, $31.33 \%$ of the participants were current alcohol drinkers. This finding is in agreement with the studies conducted among South Africans of 15 years or older, 28\% (Afr JDAS) and Axum University students, $32.8 \%$ (Gebreslasse). But, it is relatively less than the study conducted among health officer and medical students of Jimma University $36.4 \%$ (Meresa), and undergraduate Mekelle university students $41 \%$ (Abrha) [16]. As this study indicated $8.67 \%$ respondents fulfilled the criteria of substances abuse (CAGE $\geq 2)$ for alcohol. This is lower than the study conducted in Mekelle university students 22\% (Abrha) and much lower than from the reports of on Ambrose Alli University students, Ekpoma, Nigeria 66\% (Jolly) [17-21].

Besides, based on this study, $14.7 \%$ of the participants were ever Khat chewers. This finding is lower than the result obtained from a study in Haramaya University 30.3\% (Derese) and Axum University 28.7\% (Gebreslasse). Also current Khat chewers in this study were $9.33 \%$ of the study subjects, which is lower than current Khat chewing prevalence report from a study conducted among health officer and medical students of Jimma University, 33.1\% (Meressa), Axum University 27.9\% (Gebreslasse) and Mekelle University 25\% (Abrha). As this study revealed $6.7 \%$ respondents fulfilled the criteria of substances abuse (CAGE $\geq 2$ ) for Khat. This is also lower than the report among undergraduate Mekelle university students $14.8 \%$ (Abrha). Moreover unlimited production and trafficking of alcohol and Khat is imposing a difficulty to the University students who are expected to handle the socio economic and political burden of the nation.

\section{Conclusion and Recommendation}

Psychoactive substance abuse among University students was found to be higher; with alcohol and Khat the most common substances. Primary school ages were the time for half of the abusers to start extracting substances.

\section{To food medicine and health administration and control authority}

- Cultivation and trafficking of Khat should be restricted

- Responsible production and sale of alcohol including local ones should be emphasized to minimize its consumption under the age of 18 years

\section{To Ministry of Education}

- Different comprehensive activities in teaching institutions (including Universities) that focus on psychoactive substance abuse should be strengthened with special concern to primary/elementary schools

\section{Acknowledgment}

It is our delight to forward our deep appreciation to college of health sciences, Mekelle University. In addition we are grateful to all participants and data collectors.

\section{Conflict of interest among authors}

None

\section{Funding source}

This study was done with no financial source for any of the partial or complete work

\section{References}

1. Kevin EG, Amelia MA, Dawn MBF, Eric DW (2008) Heavy Drinking and Poly drug Use among College Students. Int J Drug Issues 38: 445-466.

2. Sadock BJ, Sadock VA (2007) Synopsis of Psychiatry. 10th Edition.

3. Deressa W, Azazh A (2011) Substances use and its predictors among undergraduate medical students of Addis Ababa University in Ethiopia. BMC Public Health 11: 660 .

4. Oshodi O, Aina O, Onajole A (2010) Substances use among secondary school students in an urban setting in Nigeria: prevalence and associated factors. African J Psychiatry 13: 32-57.

5. Kebede Y, Abula T, Ayele B, Feleke A, Degu G, et al. (2005) Substances Abuse For the Ethiopian Health Center Team. Ethiop Public Health Train Initiative 81.

6. Volkow ND, Li TK (2005) Drugs and alcohol: Treating and preventing abuse addiction and their medical consequences. Pharmacology and Therapeutics 108: 3-17.

7. Hansson M, Stockfelt L, Urazalin M, AhIm C, Andersson R (2008) HIVIAIDS awareness and risk behavior among students in Semey, Kazakhstan: a crosssectional survey. BMC International Health and Human Rights 2: 14.

8. Nasir EF, Astrom AN, David J, Ali RW (2008) HIV and AIDS related knowledge sources of information, and reported need for further education among dental students in Sudan-a cross sectional study. BMC Public Health 8: 286.

9. Yousafzai AW, Ahmer S, Syed E, Bhutto N, Iqbal S, et al. (2009) Well-being of medical students and their awareness on substance misuse: a cross-sectional survey in Pakistan. Annals of General Psychiatry 8: 8.

10. Abrha K (2011) Psychoactive Substance Abuse and Intention to Stop Among Students of Mekelle University, Ethiopia, May.

11. Sahraian A, Sharifian M, Omidvar B, Javadpour A (2010) Prevalence of 
Citation: Mossie TB, GebreMichael GB, Ayele AD (2015) Magnitude of Psychoactive Substance Abuse among University Students, Adigrat, North Ethiopia: Cross Sectional Study. J Psychiatry 18: 281 doi: 10.4172/2378-5756.1000281

Page 4 of 4

Substance Abuse among the Medical Students in Southern Iran. Shiraz E-Medical Journal 11

12. Derese A, Seme A, Misganaw C (2014) Assessment of Substance Use and Risky Sexual Behavior among Haramaya University Students, Ethiopia, Science Journal of Public Health 2: 102-110.

13. Lamptey JJ (2005) Socio-demographic Characteristics of Substance Abusers Admitted to a Private Specialist Clinic. Ghana Medical Journal 19.

14. Kabiru CW, Beguy D, Crichton J, Ezeh AC (2010) Self-reported drunkenness among adolescents in four sub-Saharan African countries: associations with adverse childhood experiences. Child and Adolescent Psychiatry and Mental Health 4: 17 .

15. Gebreslassie M, Feleke A, Melese T (2013) Psychoactive substances use and associated factors among Axum university students, Axum Town, north Ethiopia. BMC Public Health 13

16. Meressa K, Mossie A, Gelaw Y (2009) Effect of substance use on academic achievement of Health Officer and medical students of Jimma University, South West Ethiopia. Ethiop Journal of Health Sciences 19: 155-63.

17. Jolly O, Oyaziwo A, Samuel F, Idonijie O (2009) Drug Abuse among Students of Ambrose Alli University, Ekpoma, Nigeria. European Journal of Social Sciences 10: 88 .

18. American Psychiatric Association. Diagnostic and statistical manual of mental disorders, Text Revision (4th ed.).Washington, DC: American Psychiatric Association (2000)

19. EPHA: Emerging Public Health Problem in Ethiopia, Annual conference of The Ethiopian public Health association. Addis Ababa: EPHA; 2006.

20. Hansson M, Stockfelt L, Urazalin M, Ahlm C, Andersson R (2008) HIVIAIDS awareness and risk behavior among students in Semey, Kazakhstan: a crosssectional survey. BMC International Health and Human Rights 2: 14.

21. African Journal of Drug and Alcohol Studies (2010) 5: 107. 